\title{
Figuras do Pensamento em W. Benjamin
}

\section{Aléxia Bretas $^{1 *}$}

Resenha: MACHADO, Francisco Pinheiro. Imagem e consciência da história: pensamento figurativo em Walter Benjamin. Tradução: Milton Camargo Mota. São Paulo: Loyola, 2013. 234 p.

Lançada em dezembro último pela coleção Humanística da editora Loyola, Imagem e consciência da história: pensamento figurativo em Walter Benjamin é uma publicação a ser recebida com entusiasmo pelo público brasileiro. Afinal, corresponde à tese de doutoramento defendida por Francisco Pinheiro Machado junto ao Departamento de Filosofia da Ludwig-MaximiliansUniversität em Munique, e desde 2005 encontra-se publicada em alemão. Com a impecável tradução de Milton Camargo Mota, o volume traz a chance dos leitores brasileiros entrarem em contato com uma pesquisa que permanece relevante, primando tanto pelo rigor acadêmico quanto pela admirável clareza de uma exposição desenvolvida com lucidez, maestria e concisão. Ademais, além de expandir o horizonte de sua recepção universitária, esta edição tem o mérito de abordar o inesgotável pensamento benjaminiano a partir das sendas indicadas por uma tríplice visada. Sob a perspectiva da teoria crítica, Imagem e consciência da história propõe uma leitura da obra de Walter Benjamin pelo viés dos

$1^{*}$ Pesquisadora do IEL-UNICAMP e bolsista de pós-doutorado da FAPESP. 
reiterados esforços do autor em oferecer um contraponto à teoria tradicional, na época, representada pelo neokantismo e seus adeptos. Sob o ponto de vista da teoria da imagem, o livro de Francisco Machado alinha os escritos benjaminianos a uma tendência atual bastante prolífera de apropriação do regime imagético como recurso reflexivo e filosófico de primeira grandeza, de certa maneira, aproximando sua iniciativa da de autores notáveis como Warburg, Ginzburg, Didi-Huberman e Rancière. Finalmente, sob o olhar dos estudos históricos, esta publicação representa uma importante contribuição para o debate em torno das tensões críticas entre o passado e o presente, tomando como centro de gravidade as figuras e forças construtivas que circunscrevem a cartografia da contemporaneidade, seus dilemas, desafios e contradições inerentes.

Dividido em cinco partes dedicadas respectivamente à questão do tempo, à interpretação imagética da história, à teoria teológico-estética da linguagem, à secularização do pensamento figurativo e ao despertar como potencialização daquilo que "poderia ter sido e não foi", o livro de Francisco Pinheiro Machado percorre atentamente a obra de Walter Benjamin, buscando rastrear os pontos de convergência e refração entre os motivos da imagem e da história em seus escritos. O resultado é uma rigorosa reabilitação das configurações imagéticas como expediente corretivo das distorções epistemológicas produzidas pela hegemonia do princípio da identidade, e também políticas derivadas de três tendências ainda bastante influentes durante a primeira metade do século XX: o historicismo conservador, o marxismo vulgar e o evolucionismo socialdemocrata.

Podemos dizer resumidamente que Benjamin oferece uma 
resposta ao fenômeno concreto, catastrófico do fascismo de sua época. Ele desenvolve uma teoria da história que se volta tanto contra a neutralização de eventos passados pelo historicismo, que procura produzir uma imagem eternamente válida do passado, quanto contra o tempo homogêneo, vazio, que serve como base para a crença num progresso automático visto como evolução que corre por conta própria. ${ }^{2}$

Deste modo, contra os protocolos da neutralização da história, Benjamin arma sua ofensiva com base no entrelaçamento de duas matrizes teóricas em larga medida heterogêneas: o messianismo judaico e o materialismo dialético. Bastante polêmica, a aproximação entre a teologia e o marxismo nos escritos benjaminianos é tema de inúmeros artigos e publicações especializadas. Por seu caráter esquemático, merece destaque a posição assumida por Michael Löwy, que distingue três posturas estritamente distintas em relação ao assunto tratado: a da escola marxista representada por Bertolt Brecht, para quem as formulações teológicas de Benjamin devem ser tomadas como simples metáforas; a da escola teológica capitaneada por Gershom Scholem, que retrata o filósofo como um pensador messiânico em cujos escritos o marxismo surge apenas como uma prescindível terminologia; e a escola da contradição, que tenta harmonizar essas duas tendências inconciliáveis, resultando no fracasso de um projeto impossível, conforme os escritos de

2 PINHEIRO MACHADO, Francisco. Imagem e consciência da história: pensamento figurativo em Walter Benjamin. Tradução: Milton Camargo Mota. São Paulo: Loyola, 2013, p. 46. 
Habermas e Tiedemann deixam evidente. Löwy, no entanto, propõe uma quarta via interpretativa. Segundo ele, Benjamin é tanto marxista quanto teólogo e, como o deus romano Janus, tinha duas faces complementares: uma voltada para Moscou e outra para Jerusalém. ${ }^{3}$

Não obstante, em Imagem e consciência da história, o essencial deste debate parece ser o caráter indissoluvelmente crítico, secular e não-fundamentalista desta conexão. Neste sentido, um dos méritos da leitura proposta por Machado é o questionamento de algo que se preserva como uma verdade consensual entre intérpretes das mais diversas formações e escolas: o caráter inexoravelmente insustentável de tal aproximação. Pois como sugere Francisco Pinheiro Machado, a teologia messiânica não é, a rigor, de todo incompatível com uma certa visão marxista na qual a consciência da história se afirma, ao mesmo tempo, como consciência política. Seguindo sua argumentação, esta "ligação complexa e nada óbvia" entre materialismo histórico e teologia se revela, ao fim e ao cabo, perfeitamente viável à luz dos princípios defendidos por algumas teologias cristãs bastante influentes na América Latina como a teologia da libertação, por exemplo. Valendo-se da perspectiva adotada por teólogos como Libanio, Boff e Dussel, o autor não hesita a defender a legitimidade de uma reflexão "reinterpretativa e crítica" que surge como consciência de uma "responsabilidade profético-política", e defende seu lugar na premente tarefa de validação de uma outra concepção da história articulada do ponto de vista dos vencidos. Segundo Pinheiro Machado, esta abordagem essencialmente heterodoxa e ativa

3 Cf. LÖWY, Michael. Walter Benjamin: aviso de incêndio: uma leitura das teses "Sobre o conceito de história". São Paulo: Boitempo, 2005, p. 36. 
tem o mérito de oferecer importantes aportes para a superação tanto de um pessimismo negativo à la Adorno, quando de um messianismo ideológico desprovido de qualquer lastro social. Ao destacar a orientação indissoluvelmente prático-política da teoria benjaminiana, ele é enfático: "Ela se põe radicalmente contra toda forma de conformismo e de apatia política (...). Além disso, exige uma confrontação engajada, crítica com as diversas situações de opressão, como também uma profunda solidariedade com os esforços dos oprimidos para superar tais situações". ${ }^{4}$

Não por acaso, ao discutir o aspecto tipológico presente na formação da chamada "consciência histórica", Francisco Pinheiro Machado retoma a décima quinta tese benjaminiana para lançar luzes sobre um fato tão curioso quanto significativo: a destruição dos relógios pelos revolucionários franceses - os quais, como "novos Josués", pretendiam explodir o continuum da tradição e, assim, interromper o cortejo triunfal dos vencedores. "Quem poderia imaginar! Dizem que irritados contra a hora / Novos Josués, ao pé de cada torre / Atiraram nos relógios para parar o dia". 5 O autor esclarece o sentido desta passagem emblemática à luz da iniciativa benjaminiana de contrapor, quer ao historicismo, quer ao evolucionismo positivista, uma nova configuração histórica composta por uma espécie de justaposição de estratos

4 PINHEIRO MACHADO, Francisco, op. cit., p. 61.

5 "Qui le croirait! On dit qu'irrités contre l'heure / De nouveaux Josués, au pied de chaque tour, / Tiraient sur les cadrans pour arrêter le jour." BENJAMIN apud LÖWY, Michael, op. cit., p. 123. Os versículos aos quais o autor se refere nesta passagem são os seguintes: "Então Josué falou ao Senhor, (...) que disse em presença de Israel: 'Sol, detém-te sobre Guibeon, Lua, sobre o vale de Aialon! E o Sol parou, e a Lua imobilizou-se até a nação ter se vingado dos seus inimigos". Ver Josué 10, 12-13. 
temporais à espera de uma interpretação transformadora. "No pano de fundo desses versos distingue-se uma forma de percepção e interpretação da história pela qual um evento atual é compreendido e interpretado como um nova irrupção de um acontecimento passado ou de um conteúdo histórico". ${ }^{6}$ Porém, segundo ele, tal conjunção só se torna efetivamente legível por um breve instante, "perigoso e fugaz", que Benjamin designa como "instante da cognoscibilidade" ou "tempo de agora" (Jetztzeit). Neste sentido, sua ainda incipiente teoria da "dialética na imobilidade" (Dialektik im Stillstand) pretende dar contra de abarcar os antagonismos ou tensões insolúveis nas quais os conflitos históricos se encontram constelados, sem se render, seja aos misteriosos arcanos da religião ou à unidimensional ideologia do progresso.

A fim de validar a concepção benjaminiana de uma representação figurativa da história, Machado recorre à crítica tipológica de Johann Georg Hamann. Através de uma peculiar abordagem da linguagem, tais escritos têm o mérito de questionar a pertinência do projeto iluminista de tratar a história de forma universal e abstrata como simples teoria, oferecendo subsídios para se legitimar a configuração do acontecimento não como mera facticidade privada de seu contexto original, senão como "imagem" - vale dizer, necessariamente secular e concreta. Esta, por sinal, é a chave para a compreensão de um topos recorrente nos textos tardios de Benjamin, apresentados por Machado como uma espécie de desdobramento laicizante de suas considerações estético-epistemólogicas no Trauerspielbuch. Assim, a constelação "nome-ideia-origem-mônada" presente

6 PINHEIRO MACHADO, Francisco, op. cit., p. 64. 
no livro do barroco mantém seu significado essencial de crítica radical às categorias tradicionais encampadas pelo sistema, adquirindo, além disso, um vetor indelevelmente social e político nas Passagens.

Não é que o passado jogue sua luz sobre o presente ou o presente sua luz sobre o passado, mas a imagem é, antes, aquilo em que o ocorrido se encontra com o agora como um relâmpago, formando uma constelação. Em outras palavras: a imagem é a dialética em estado de repouso. Pois, enquanto a relação do presente com o passado é puramente temporal, a do ocorrido com o agora é dialética: não de natureza temporal, mas imagética. Apenas imagens dialéticas são autenticamente históricas, isto é, não arcaicas. A imagem lida, vale dizer, a imagem no agora da cognoscibilidade carrega no mais alto grau o selo do momento crítico, perigoso, que se encontra na base de toda leitura. ${ }^{7}$

Portanto, como Francisco Pinheiro Machado elucida, a imagem dialética pode ser definida como uma conjunção imagética entre o ocorrido e o agora. Apresentando-se inicialmente de modo lampejante, involuntário e imediato ao sujeito da história, ela lança aos contemporâneos o apelo para ser reconhecida, interpretada e expressa, precisamente a partir de suas heterogeneidades e contradições internas. Deste modo, o ocorrido é resgatado invariavelmente em uma atualidade única, assim como o instante visado por ele. Isso, no entanto, não implica na pura e simples

7 BENJAMIN, Walter apud MACHADO, Francisco Pinheiro, op. cit., p. 155. 
repetição dos fatos passados, mas, sim, na emergência de uma constelação inteiramente nova, que interrompe e modifica indelevelmente a trajetória uniforme e contínua da historiografia oficial - como em uma espécie de "montagem".

Entretanto, por guardar uma relação de parentesco indelével com as "imagens oníricas", o tratamento benjaminiano das imagens dialéticas foi duramente recebido pelo Instituto de Pesquisa Social e, em particular, por Adorno. Consternado pela presença de categorias semelhantes àquelas empregadas por teóricos do mito e das imagens arcaicas como Jung e Klages, o filósofo é taxativo ao desqualificar a ocorrência das configurações oníricas no núcleo filosófico do trabalho das Passagens. ${ }^{9}$ Em carta de 2 de agosto de 1935 onde comenta o "Exposé de 1935", Adorno pondera: "Se você desloca a imagem dialética para o interior da consciência como 'sonho', não somente priva de mágica o conceito, domesticando-o, mas também o despe precisamente daquele crucial poder objetivo que o legitimaria em termos materialistas". ${ }^{10}$ Em correspondência na qual, apesar de tudo, ratifica sua enorme amizade por Adorno e Gretel, Benjamin não se furta a responder às incisivas críticas do colega:

8 Sobre o sentido das imagens oníricas nos escritos benjaminianos, ver BRETAS, Aléxia. A constelação do sonho em Walter Benjamin. São Paulo: Humanitas, 2008.

9 A este respeito ver ADORNO, Theodor. Correspondência, 1928-1940 / Theodor W. Adorno, Walter Benjamin. Tradução: José Marcos Mariani de Macedo. São Paulo: Editora Unesp, 2012; e BRETAS, Aléxia. Do deserto de gelo da abstração ao filosofar concreto: correspondência Adorno-Benjamin (1928-1940). Trans/Form/Ação, vol. 36, nº 3 (2013).

10 ADORNO, Theodor, op. cit., p. 177. 
A imagem dialética não copia simplesmente o sonho jamais foi minha intenção afirmar isso. Mas me parece claro que ela contém as instâncias, as irrupções da vigília, e que é precisamente a partir desses loci que é criada sua figura, como a de uma constelação a partir dos pontos luminosos. Aqui também, portanto, um arco precisa ser retesado, e uma dialética forjada: aquela entre imagem e vigília. $^{11}$

E aqui o autor toca numa problemática que permanecerá sem solução em sua teoria: a construção de uma dialética entre o sonho e o despertar histórico. Atento a seu valor estratégico para a fundamentação do arcabouço conceitual do trabalho das Passagens, Francisco Pinheiro Machado dedica todo o quinto capítulo de Imagem e consciência da história ao debate em torno das implicações filosóficas e, no limite, políticas do instante crítico do despertar. Não por acaso, ao designar seu novo método historiográfico como "técnica do despertar", o próprio Benjamin explicita:

O método novo, dialético, da ciência histórica se apresenta como a arte de experimentar o presente como mundo da vigília, ao qual aquele sonho que chamamos de ocorrido se refere verdadeiramente. Elaborar o ocorrido na lembrança do sonho! - Portanto: lembrar e despertar são estreitamente aparentados. Pois despertar é a revolução copernicana, dialética da rememoração. ${ }^{12}$

11 BENJAMIN, Walter in: ADORNO, Theodor, op. cit., p. 195.

12 BENJAMIN, Walter. Passagens apud MACHADO, Francisco Pinheiro, 
Conforme Pinheiro Machado elucida, a elaboração benjaminiana sugere claramente que a avaliação dos elementos oníricos no despertar não só serve de modelo para a lembrança histórica, mas também produz um vínculo indelével entre a historiografia e a política; ela é "cânon da dialética" e por isso é um modelo para o pensador e uma obrigação para o historiador. Assim é que a fim de ressaltar a relação inalienável entre o sonho, o despertar e o surgimento de uma nova configuração da história no projeto das Passagens, Pinheiro Machado, seguindo os passos de Benjamin, recorre à teoria freudiana da interpretação dos sonhos, bem como à descrição proustiana do momento do despertar como ponto de virada para aquilo que o autor se refere como revolução copernicana e dialética da rememoração. Ele compara:

O que Proust quer dizer com a mudança experimental dos móveis no estado de semidormência matinal, o que Bloch percebe como a obscuridade do instante vivido, nada mais é do que aquilo que se estabelecerá aqui no plano da história, e coletivamente. Existe um saber ainda-nãoconsciente do ocorrido, cuja promoção tem a estrutura do despertar. ${ }^{13}$

Deixando patente a iniciativa de transpor para o plano coletivo da prática política suas reflexões preparatórias sobre as imagens dialéticas, o autor busca legitimar uma certa "astúcia"

op. cit., p. 190.

13 BENJAMIN, Walter. Passagens. Tradução: Tradução: Irene Aron e Cleonice Paes Barreto Mourão. Belo Horizonte: Editora UFMG; São Paulo: Imprensa Oficial do Estado de São Paulo, 2006, p. 433-434. 
como método de trabalho, propondo a utilização dos elementos do sonho na articulação de uma interpretação transformadora catalizada pelo despertar histórico. Para isso, nas palavras de Francisco Pinheiro Machado, "uma forma secularizada do pensamento figurativo, como a de Benjamin, revela-se imprescindível". ${ }^{14}$ Pois ao apoiar-se sobre uma relação imagética e tensa entre o sonho e o despertar, o passado e o agora, ela torna possível uma dinâmica irredutivelmente aberta da história.

14 PINHEIRO MACHADO, Francisco, op. cit., p. 223. 